OPEN ACCESS

\title{
Enhanced Fast Charging and Reduced Lithium-Plating by Laser- Structured Anodes for Lithium-Ion Batteries
}

To cite this article: Jan Bernd Habedank et al 2019 J. Electrochem. Soc. 166 A3940

View the article online for updates and enhancements. 


\title{
Enhanced Fast Charging and Reduced Lithium-Plating by Laser-Structured Anodes for Lithium-Ion Batteries
}

\author{
Jan Bernd Habedank, $\mathbb{1}^{\mathrm{Z}}$ Johannes Kriegler, and Michael F. Zaeh
}

Technical University of Munich, Institute for Machine Tools and Industrial Management, 85748 Garching, Germany

\begin{abstract}
Within this paper we report on a lithium-ion battery with laser-structured graphite anodes, alleviating current drawbacks of lithiumion batteries such as the reduced discharge capacity at high C-rates and the on-set of lithium-plating during fast charging. These issues are intensified at low temperatures, as reaction and diffusion kinetics decelerate, which is why a focus of the presented work lies on low temperature performance. Electrochemical impedance spectroscopy was used to show a reduction in the impedances of cells with laser-structured anodes in comparison to their conventional counterparts. The discharge capacity retention at high C-rates was enhanced by up to $27 \%$ compared to conventional cells, proving potential for high power applications. For the cells with laserstructured anodes, the on-set of lithium-plating at $0^{\circ} \mathrm{C}$ was observed at higher charging C-rates by analyzing the voltage relaxation after charging. At $-15^{\circ} \mathrm{C}$, a smaller amount of plated lithium was detected, even though lithium-plating could not be entirely avoided. Laser structuring also enabled shorter charging times, as the upper cutoff voltage was reached at a higher SOC. The results point out that laser structuring of the anode improves the fast charging capability of lithium-ion cells, especially under demanding operating conditions.

(C) The Author(s) 2019. Published by ECS. This is an open access article distributed under the terms of the Creative Commons Attribution 4.0 License (CC BY, http://creativecommons.org/licenses/by/4.0/), which permits unrestricted reuse of the work in any medium, provided the original work is properly cited. [DOI: 10.1149/2.1241915jes]

Manuscript submitted August 22, 2019; revised manuscript received October 31, 2019. Published November 26, 2019.

Lithium-ion batteries (LIBs) are the key-components for the success of electric vehicles and a sustainable energy economy. Their performance is highly dependent on the charge and mass transport kinetics between the porous electrodes. ${ }^{1}$ At low temperatures, the cell internal resistances rise due to a decreasing ionic conductivity of the liquid electrolyte, sluggish charge transfer processes on the interfacial area between the active material and the electrolyte, and slow lithium diffusion within the active material. ${ }^{2}$ The increasing resistances result in high overpotentials and electrode polarization during cell operation. ${ }^{3}$ For discharge, the consequences are a reduced deployable capacity and an amplified heat generation. However, high overpotentials during charging can cause the deposition of metallic lithium (Li-plating) onto the anode surface, specifically when the anode surface potential falls below $0 \mathrm{~V} .{ }^{4} \mathrm{Li}$-plating has been reported to accelerate the ageing of the $\mathrm{LIB}^{5}$ and presents severe safety risks due to dendrite formation. ${ }^{6}$ Among others, a low anode-to-cathode capacity ratio, low temperatures, high charging rates, and overcharging favor the deposition of metallic lithium, as these factors have an effect on the anode kinetics and the diffusion rate. ${ }^{2}$ Thus, the charging currents have to be strictly limited, especially at low temperatures. While in laboratory cells the individual electrode potentials can be measured by applying reference electrodes, the detection of Li-plating in commercial full cells is challenging. The Li-plating process is partially reversible and some of the deposited lithium re-intercalates into the graphite when a relaxation phase occurs after charging. During this period, a distinctive voltage plateau can be observed, making the on-set of Li-plating detectable with nondestructive electrochemical methods. ${ }^{7}$ Similar observations were made when skipping the relaxation phase and examining the voltage in the discharge process after fast-charging at low temperatures instead. ${ }^{8}$ In this case, the plated lithium mostly dissolves into the electrolyte before it re-intercalates into the anode (Li-stripping). ${ }^{9} \mathrm{By}$ analyzing the differential voltage during this Li-stripping process, ${ }^{10}$ the identification of previously plated lithium can be further facilitated. ${ }^{11}$

Conventional electrodes of LIBs consist of active material particles, binders and conductive agents which are coated onto metallic current collector foils. While there are many possible chemistries for the cathode, such as $\mathrm{LiCoO}_{2}, \mathrm{LiFePO}_{4}$ or $\mathrm{LiNi}_{\mathrm{x}} \mathrm{Mn}_{\mathrm{y}} \mathrm{Co}_{\mathrm{z}} \mathrm{O}_{2}(\mathrm{NMC}$, $\mathrm{x}+\mathrm{y}+\mathrm{z}=1$ ), the majority of anodes in commercially available cells are made of carbon (mostly graphite). In cell production, the electrode constituents form a porous layer with a tortuous void volume which is filled by the liquid electrolyte. The effect of the porous microstructure on the ion transport is commonly described by the MacMullin

${ }^{\text {z} E-m a i l: ~ j a n . h a b e d a n k @ i w b . m w . t u m . d e ~}$ number $N_{M}$

$$
N_{M}=\frac{\kappa}{\kappa}_{e f f}
$$

which provides a relation between the ionic conductivity $\kappa$ and the effective conductivity $\kappa_{e f f}$ through the porous media. From a geometrical perspective, the tortuosity $\tau$

$$
\tau=\frac{d_{\text {path }}}{d}
$$

is a characteristic value for describing the ion transport restraint of the porous electrode microstructure, where $d_{\text {path }}$ is the actual transport path of an ion through the electrode and $d$ is the direct path between the point of de-intercalation and intercalation while charging or discharging. ${ }^{12}$ The tortuosity $\tau$ has been reported to have a major influence on diffusion and concentration overpotentials within the electrode structure. ${ }^{12}$ As the lithium transport into and out of the electrode is impeded, large concentration gradients are formed, creating a strongly inhomogeneous charge carrier distribution. ${ }^{13}$ This effect predominantly occurs in anodes containing flake-like graphite particles ${ }^{14}$ which are commonly used as anode material in LIBs due to their lower cost compared to spherical graphite, which is roughly three times more expensive due to high scrap rates in spherical graphite production. ${ }^{15}$ Due to the calendering process in LIB production, the preferential orientation of the graphite flakes is parallel to the current collector and perpendicular to the diffusion direction through the electrode. ${ }^{16}$ This generates a spatial tortuosity anisotropy and creates particularly long diffusion pathways $d_{\text {path }}$ through the electrode. ${ }^{17}$ Among many other parameters, ${ }^{18}$ the ionic resistance within LIB electrodes can be assessed in situ by measuring the cell impedance using electrochemical impedance spectroscopy (EIS), ${ }^{19}$ enabling a calculation of the tortuosity. ${ }^{12} \mathrm{By}$ measuring the impedance of cells at different states of charge (SOC) and temperatures, conclusions concerning the kinetics of lithium ions within the electrodes can be drawn. ${ }^{20-22}$ Impedance spectra for LIB are represented in the form of Nyquist plots and typically consist of two partially overlapping semicircles and a straight sloping line in the low frequency region. ${ }^{23,24}$ As the effective impedances of cathode and anode in full cells cannot be precisely distinguished, the recorded EIS spectra represent the total impedance of the electrochemical cell. The size of the semicircles provides information about the magnitude of the resistances resulting from the charge transfer processes between the electrodes and the electrolyte as well as the passing through the solid electrolyte interface (SEI). ${ }^{25}$ When measuring at very low frequencies, the resulting quasi-linear slope can be related to the solid-state diffusion processes within the active material particles. ${ }^{26,27}$ At low 
temperatures ${ }^{20,21,24}$ and low SOCs, ${ }^{27,28}$ the charge transfer resistances within the cell rise, resulting in an increase in the overall impedance, which can be seen in the EIS spectra.

One promising way for enhancing the lithium transport in LIBs is the creation of three-dimensional (3D) electrode structures, aiming at a reduction of the average electrode tortuosity $\tau$. Thereby the effective diffusion of lithium in the electrolyte $D_{\text {eff }}$ can be increased according to

$$
D_{\text {eff }}=\frac{\varepsilon}{\tau} D_{0}
$$

where $\varepsilon$ is the electrode porosity and $D_{0}$ is the diffusion coefficient of lithium in the liquid electrolyte. The 3D-structures can be created by laser pulses which precisely remove a small fraction of the coating. It has been reported that the shortened ion transport pathways lead to a reduced cell resistance and thereby improve the discharge rate capability compared to conventional unstructured electrodes. ${ }^{29,30}$ This effect was computationally analyzed in a numerical model, precisely depicting the structure arrangement and dimensions. ${ }^{30}$ The introduction of additional pores by laser radiation offers a high flexibility regarding the structure type (e.g. grid, line, or hole structures) and the respective spacing between the structures. Also, the dimensions of each individual structure can be adjusted. ${ }^{29}$ Generally speaking, more particles are removed close to the surface of the electrode, resulting in conical structures which narrow toward deeper parts of the electrode. ${ }^{31}$ The size and the distribution of the structures have a strong effect on the cell-internal resistance ${ }^{32}$ and, thus, the electrochemical performance. When evaluating structure geometries that lead to a comparable total amount of removed electrode material, finer structures have proven to be more beneficial than coarser structures. ${ }^{33}$ In contrast to other concepts such as co-extruded ${ }^{34}$ or sintered ${ }^{35}$ as well as 3D-printed electrodes, ${ }^{36}$ the laser structuring process can be applied to conventionally coated electrodes. From a production point of view, establishing the laser structuring process in the industrial fabrication of LIBs shows higher potential for in-line implementation (roll-toroll processing) into the existing production chain and is associated with lower cost. Cost calculations with regard to laser structuring of electrodes based on scenarios by Wood et al. ${ }^{37}$ even predict potential savings in LIB production which may surpass the additional costs due to laser machinery, maintenance, and operation. ${ }^{38}$ These potential savings result from a reduction in the electrolyte wetting time ${ }^{39}$ and the application of electrodes with a higher areal loading and energy density.

\section{Objectives and Approach}

As described in the introductory section, Li-plating is one of the major obstacles in the development of LIBs with fast-charging capa- bility. This paper presents a new approach to electrode design in order to reduce the cell impedance and, thus, the overpotentials during charging and discharging. The generation of structures in the anode by means of short laser pulses (pulse duration $150 \mathrm{ps}$ ) aims at improving the ion transport between anode and cathode (Fig. 1).

As structures, holes in a hexagonal pattern with a center point distance of $100 \mu \mathrm{m}$ were created. The laser process was designed to achieve an aspect ratio of the structures of $>1.5$, which is defined by the ratio of the structure depth over the structure diameter at the electrode surface. Based on previously published data, the hexagonal hole pattern represents the best geometric structure to balance the conflict between the removal of active material and the reduction of the anode tortuosity. ${ }^{30,31} \mathrm{By}$ analyzing the electrochemical impedance spectra at temperatures of $-15^{\circ} \mathrm{C}, 0^{\circ} \mathrm{C}$, and $25^{\circ} \mathrm{C}$, the impedances of coin cells containing laser-structured anodes ( $\mathrm{S} 1$ and $\mathrm{S} 2$ ) were compared to their conventional counterparts (R1 and R2). Subsequently, the effects of the structuring on the discharge C-rate capability were examined. In the next step, the charging behavior was analyzed with a special focus on the detection of Li-plating. For this purpose, the voltage relaxation after charging at $\mathrm{C}$-rates from $0.1 \mathrm{C}$ to $2 \mathrm{C}$ and ambient temperatures of $-15^{\circ} \mathrm{C}, 0^{\circ} \mathrm{C}$, and $25^{\circ} \mathrm{C}$ was monitored and indications of Li-plating were observed. Finally, the charging durations required to fully charge the LIBs were assessed in order to evaluate the potential for improvements in fast charging under demanding low-temperature conditions. In Fig. 1a and Fig. 1b, the internal setup of a LIB with laser-structured graphite anodes and conventional unstructured NMC cathodes is illustrated. Fig. 1c shows a top-view scanning electron microscopy (SEM) image of a laser-structured graphite anode as well as a close-up image of a single laser-induced hole structure. More detailed information on the materials and processes used can be found in the subsequent Materials and Methods section.

\section{Materials and Methods}

Materials.-All coin cell components including the coated electrode materials were purchased from commercial sources to ensure a high comparability of the base materials (type 2032 coin cell cases, springs, and spacers: MTI Corporation, USA; glass fiber separator: Type 691, VWR, USA; cathodes: Umicore NV/SA, Belgium; anodes: SEI Corporation, Japan). The electrode characteristics, as provided by the electrode manufacturers, are presented in Table I. Further details on the precise material types (e.g. type of binder, type of conductive carbon) and the respective production processes were not disclosed to the authors for reasons of confidentiality.

Laser structuring of the anodes.-A pulsed Nd:YAG fiber laser (YLPP-1-150V-30, IPG Photonics Corporation, USA) with discrete tunable pulse durations from $150 \mathrm{ps}$ to $5 \mathrm{~ns}$ was used to generate the a)

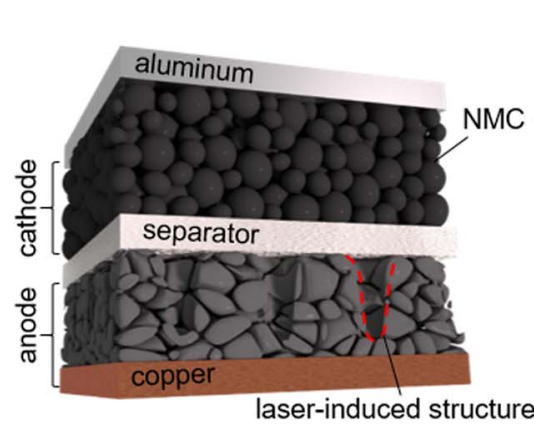

b)

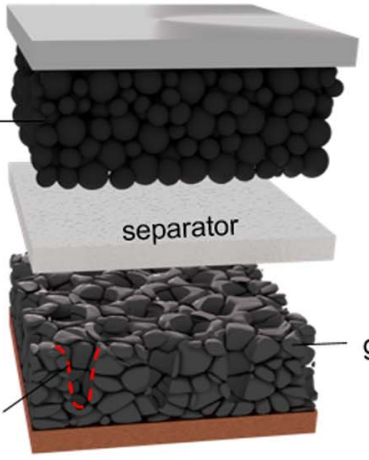

c)

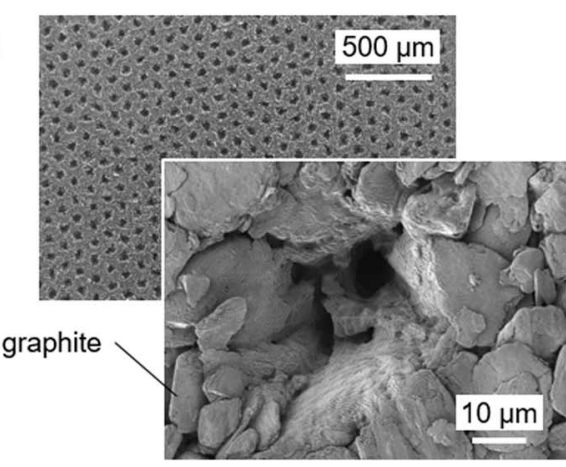

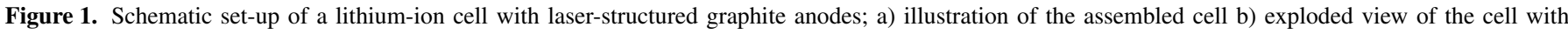

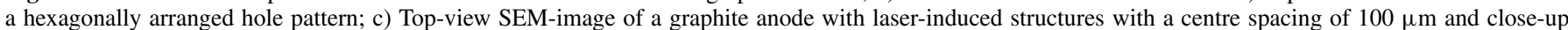

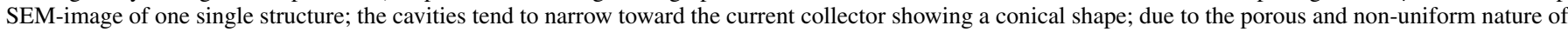
the electrode coating each structure shape is unique. 
Table I. Electrode specifications.

\begin{tabular}{lll} 
& Cathode & Anode \\
\hline Active material & NMC $(1 / 1 / 1)$ & Graphite \\
& $93.0 \mathrm{wt} \%$ & $92.5 \mathrm{wt} \%$ \\
Conductive carbon & $3.0 \mathrm{wt} \%$ & $0.5 \mathrm{wt} \%$ \\
Binder & $4.0 \mathrm{wt} \%$ & $7.0 \mathrm{wt} \%$ \\
Feature & & \\
Capacity loading & $2.748 \mathrm{mAh} / \mathrm{cm}^{2}$ & $3.606 \mathrm{mAh} / \mathrm{cm}^{2}$ \\
Weight loading & $20.38 \mathrm{mg} / \mathrm{cm}^{2}$ & $12.99 \mathrm{mg} / \mathrm{cm}^{2}$ \\
Loading deviation & $\pm 2.5 \%$ & $\pm 3.0 \%$ \\
Packing density & $2.08 \mathrm{~g} / \mathrm{cm}^{3}$ & $1.038 \mathrm{~g} / \mathrm{cm}^{3}$ \\
Porosity & approx. $32 \%$ & approx. $32 \%$ \\
Electrode thickness & $69 \mu \mathrm{m}$ & $70 \mu \mathrm{m}$ \\
Thickness deviation & $\pm 2 \mu \mathrm{m}$ & $\pm 2 \mu \mathrm{m}$
\end{tabular}

microstructures by local selective ablation of the anode material. The ablated particles were removed by a suction nozzle. The pulse duration was set to 150 ps with a pulse repetition frequency of $1200 \mathrm{kHz}$, an average power of $3 \mathrm{~W}$, and a processing time of $0.45 \mathrm{~ms}$ per structure. The laser beam was deflected by scanning optics (Racoon 21, ARGES, Germany) and focused by an F-theta lens (S4LFT0080/126, Sill Optics, Germany) with a focal length of $80 \mathrm{~mm}$. Thereby, a mean focal diameter of $27.1 \mu \mathrm{m}$ was achieved over the full power range of the laser system and determined using a beam measuring system (MicroSpotMonitor, Primes, Germany). A scanning electron microscope (JCM-600, JEOL, Germany) was used to measure the structure diameter at the top of the electrode. An average structure diameter of approx. $40 \mu \mathrm{m}$ on the electrode surface was observed, while the structures narrowed toward deeper segments of the electrode (cp. Fig. 1). The depth of the structures was measured with a laser scanning microscope (VK 9710 , Keyence, Germany) and accounted for over $90 \%$ of the total electrode thickness, occasionally revealing the current collector. No significant changes in the mechanical properties of the electrodes were observed. This was attributed to the low heat input by the short-pulse laser radiation. Thus, the binder, which is responsible for the cohesion of the electrode, was not detectably vaporized or degraded beyond the actual structure diameter. All subsequent handling processes in the assembly of the coin cells could be carried out unaltered.

Cell assembly and formation.-The coin cells (type 2032) were assembled in a dry room (dew point $<-40^{\circ} \mathrm{C}$ ). Before cell assembly, the electrodes were dried for 12 hours at $120^{\circ} \mathrm{C}$ in a vacuum oven. All other cell components were dried overnight at $60^{\circ} \mathrm{C}$ in an oven within the dry room atmosphere. Two cell types were manufactured: reference cells with conventional anodes and conventional cathodes, and cells with laser-structured anodes and conventional cathodes. The circular cathode electrodes were $14 \mathrm{~mm}$ in diameter while the anode coins were $15 \mathrm{~mm}$ in diameter to ensure a complete coverage of the cathodes by the anodes. The diameter of the glass microfiber separator was $16 \mathrm{~mm}$ to avoid internal short circuits. The conventional electrodes had an area specific capacity ratio between anode and cathode of approx. 1.31, while the cells comprising structured electrodes showed a capacity ratio of approx. 1.24 due to anode material removal. The electrolyte (LP572, BASF, Germany) consisted of ethylene carbonate (EC) and ethyl-methyl-carbonate (EMC) in a ratio of 3:7 with $1 \mathrm{M}$ lithium-hexaflourophosphate $\left(\mathrm{LiPF}_{6}\right)$ and $2 \%$ vinylene carbonate (VC). After assembly, the cells went through formation by charging and discharging them five times at approx. $0.1 \mathrm{C}$ in a laboratory battery testing system (CTS, BaSyTec, Germany). The measured capacity in the last formation cycle was used for referencing purposes, i.e. to define an individual nominal capacity for each cell. During formation, no negative influence on the initial capacity by laser structuring was observed as all the nominal cell capacities showed a negligible standard deviation of $0.048 \mathrm{mAh}$ around a mean capacity of $2.93 \mathrm{mAh}$, see Table II.

\begin{abstract}
Table II. Coulombic efficiencies (CE) of the first and second formation cycle and nominal cell capacities after the fifth formation cycle.
\end{abstract}

\begin{tabular}{llll} 
Cell name & CE cycle 1 & CE cycle 2 & Capacity after formation \\
\hline R1 & $87.54 \%$ & $99.17 \%$ & $2.96 \mathrm{mAh}$ \\
R2 & $87.59 \%$ & $98.65 \%$ & $2.85 \mathrm{mAh}$ \\
S1 & $86.74 \%$ & $98.30 \%$ & $2.92 \mathrm{mAh}$ \\
S2 & $86.86 \%$ & $98.44 \%$ & $2.97 \mathrm{mAh}$
\end{tabular}

In particular, no indications of a significantly increased SEI formation were detected as the coulombic efficiencies (CE) in the first and second formation cycles do not deviate strongly (Table II). This may be explained by the fact that, although the macroscopic and therefore exposed surface area of the electrode was enhanced, graphite particles were ultimately removed by the laser ablation process. These removed graphite particles were therefore not subject to SEI formation. A variation of the material system or the structure geometry could change the ratio of the counteracting influences regarding SEI formation described above. Further studies on SEI formation will be performed to substantiate this interpretation of the measurement data.

Electrochemical impedance spectroscopy.-For the EIS measurements, a potentiostat (Interface 5000E, Gamry Instruments, USA) was used. Before every measurement, a rest period of $>1 \mathrm{~h}$ was applied to avoid a falsification of the results by cell polarization. Every measurement started with the recording of the OCV, which was performed for $15 \mathrm{~s}$. Subsequently, the impedance was recorded in the frequency range from $100 \mathrm{kHz}$ to $1 \mathrm{~Hz}$ with 10 measurement points per decade.

Discharge rate capability tests.-To determine the discharge rate capability, the cells were cycled between $2.7 \mathrm{~V}$ and $4.2 \mathrm{~V}$ at different temperatures and increasing C-rates (Fig. 3). At a temperature of $25^{\circ} \mathrm{C}$, the maximum $\mathrm{C}$-rate was set to $10 \mathrm{C}$, while at $0^{\circ} \mathrm{C}$ and $-15^{\circ} \mathrm{C}$ the maximum $\mathrm{C}$-rate was set to $5 \mathrm{C}$ in order to avoid excessive stress and cell ageing. Charging was done using a constant-current/constant-voltage (CCCV) procedure. For the corresponding discharge rates up to $1 \mathrm{C}$, an equal charging current was used in the $\mathrm{CC}$ phase. For discharge cycles $>1 \mathrm{C}$, the charging current was held constant at $1 \mathrm{C}$ to avoid premature ageing and $\mathrm{Li}$-plating. The $\mathrm{CV}$ phase was terminated when the charging current fell below $0.01 \mathrm{C}$. No rest period between charging and discharging was applied. Discharging was performed using a constant current $(\mathrm{CC})$ procedure.

Detection of Li-plating. - The tests for the detection of Li-plating were based on the identification of voltage plateaus in a relaxation phase after $\mathrm{CCCV}$ charging. In the $\mathrm{CC}$ phase, different currents were applied and also the termination criteria for the $\mathrm{CV}$ phase were adjusted. In case of the $0.1 \mathrm{C}$ and $0.5 \mathrm{C}$ charging current in the $\mathrm{CC}$ phase, a $0.05 \mathrm{C}$ cutoff current in the $\mathrm{CV}$ phase was chosen, while in case of the $1 \mathrm{C}$ and $2 \mathrm{C}$ charging currents in the $\mathrm{CC}$ phase, a $0.2 \mathrm{C}$ cutoff current in the $\mathrm{CV}$ phase was applied. The latter termination criterion for the $\mathrm{CV}$ phase was used in order to achieve comparable durations of the $\mathrm{CV}$ phases. Equal termination criteria would have resulted in very long $\mathrm{CV}$ phases for the faster charging processes (1C and 2C), which would have strongly altered the significance of the results with regard to $\mathrm{Li}$ plating as lithium re-intercalation also would have happened during the CV phase.

\section{Influence of Laser Structuring on Cell Impedance}

In Fig. 2, the Nyquist plots obtained from EIS measurements of LIBs with laser-structured anodes $(\mathrm{S} 1, \mathrm{~S} 2)$ and conventional anodes $(\mathrm{R} 1, \mathrm{R} 2)$ at an $\mathrm{OCV}$ of $3.7 \mathrm{~V}$ are presented. Three ambient temperatures of $25^{\circ} \mathrm{C}, 0^{\circ} \mathrm{C}$ and $-15^{\circ} \mathrm{C}$ were analyzed. Please note that the presented measurements do not aim at quantitative statements or 

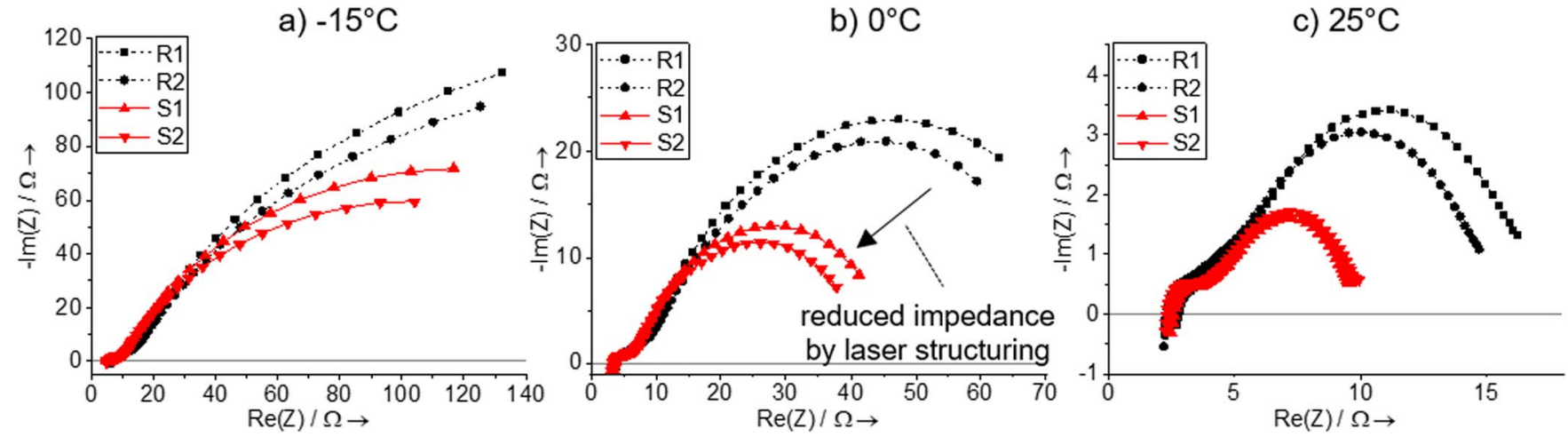

Figure 2. Electrochemical Impedance Spectra in a measurement frequency range of $100 \mathrm{kHz}$ to $1 \mathrm{~Hz}$, recorded at an $\mathrm{OCV}$ of $3.7 \mathrm{~V}$ and temperatures of a) $-15^{\circ} \mathrm{C}$, b) $0^{\circ} \mathrm{C}$, and c) $25^{\circ} \mathrm{C}$ for laser-structured $(\mathrm{S} 1, \mathrm{~S} 2)$ and reference cells $(\mathrm{R} 1, \mathrm{R} 2)$; a significant reduction in the impedance at all measured temperatures was achieved by laser structuring; due to the high impedance at a temperature of $-15^{\circ} \mathrm{C}$ the second semi-circle is only visible partly in the applied frequency regime.

models for the electrochemical processes within the cell but at a qualitative comparison of the impedances of the two different cell types at varying temperatures. As the properties of the cathodes as well as other cell parameters were kept constant in all cells, the variances in the EIS spectra can only be attributed to the additional laser-induced macroscopic pores in the anodes.

As described in the introductory section of this paper, at very low frequencies, the impedance spectra of intercalation battery electrodes represent the transport of charge carriers in the solid phases. ${ }^{40}$ As the graphite microstructure and, thus, the solid-state diffusion characteristics were not altered, the low frequency domain $(<1 \mathrm{~Hz})$ was not considered in the presented experiments. Please also note the different scales of the individual Nyquist plots. In accordance with the literature, an increased impedance with decreasing temperature was observed. This can be attributed to slower lithium diffusion kinetics and higher charge transfer resistances within the cells. When analyzing Fig. $2 \mathrm{c}\left(25^{\circ} \mathrm{C}\right)$, the characteristic Nyquist plot for LIBs consisting of two semicircles can be identified. The first semicircle is significantly smaller than the second for both laser-structured and conventional cells. A reduction of the temperature to $0^{\circ} \mathrm{C}$ (Fig. 2b) led to an overall increase of the impedance, while the general shape of the graph was maintained. The impedance increased even further when the temperature was lowered to $-15^{\circ} \mathrm{C}$ (Fig. 2a). While at $0^{\circ} \mathrm{C}$ both semicircles are still visible, at $-15^{\circ} \mathrm{C}$, the second semicircle is truncated due to the minimum applied measuring frequency of $1 \mathrm{~Hz}$ (the slight curvature of the plots in the direction of lower frequencies indicates that the second half circle only starts here). For all plots it becomes apparent that the impedance of cells with laser-structured anodes was considerably lower than that of cells with conventional electrodes. While no significant influence on the high frequency resistance (HFR) was noticed, the impedances in the semi-circle region of the Nyquist plots were significantly lower. This range is usually attributed to charge transfer processes, which comprise the lithium transport from the liquid into the solid phase and vice versa. Smaller semi-circles therefore mean that this charge transfer is associated with lower resistance, which may have various possible origins. On the one hand, the structuring results in a higher mean porosity, which in turn provides a better accessibility of the graphite particles for the charge transfer. Since the additional pores open toward the electrode surface due to their characteristic shape, the average porosity is further decreased in proximity of the electrode surface. This gradient in porosity additionally enhances the abovementioned effect. These findings indicate that laser structuring may have a positive influence on the charge transport behavior and, thus, on the fast charging and discharging performance of the cell. As already indicated above, a detailed modelling of the complex resistances will be carried out in future work in order to investigate the origin of the impedance reduction more closely. However, since this paper mainly aims to outline the potentials of the laser structuring of the anode with regard to fast charging, we only provide comparative observations here.

\section{Enhanced Discharge Rate Capability}

In the previous section, significantly reduced impedances for the laser-structured electrodes were determined by EIS. The amount of charge provided by lithium-ion cells during discharge depends on the discharge current. This interrelation has its origin in the cellinternal resistances. A reduction in these resistances therefore leads to an increase in the amount of charge provided. To quantify the influence of structuring, discharge rate tests were performed on cells with conventional anodes and the results were compared to cells with laser-structured anodes at different temperatures $\left(25^{\circ} \mathrm{C}, 0^{\circ} \mathrm{C},-15^{\circ} \mathrm{C}\right)$ (Fig. 3). To ease the comparison, the provided discharge capacities were normalized to the value measured at a low discharge rate of $0.1 \mathrm{C}$ in the first discharge cycle after cell formation. Since both the conventional and the laser-structured cells showed only a very small deviation in capacity (cp. Table II), we do not consider the validity of the results as falsified by the normalization. Low temperatures generally limit the rate capability as charge and mass transport processes decelerate. The measurements presented here are in agreement with this relationship. At all temperatures, enhancements in rate capability were observed due to laser structuring. The level of improvement through laser structuring varied in strong dependence of the temperature. At $25^{\circ} \mathrm{C}$, a maximum increase of approx. $9 \%$ in the delivered charge could be achieved by anode structuring. At $0^{\circ} \mathrm{C}$ the maximum increase was approx. $21 \%$ compared to unstructured cells, while at $-15^{\circ} \mathrm{C}$ the $\max$ imum improvement was approx. $27 \%$. Depending on the temperature, these maxima were measured at different $\mathrm{C}$ rates. While the best results at $-15^{\circ} \mathrm{C}$ were already observed at $2 \mathrm{C}$, the maxima at $0^{\circ} \mathrm{C}$ and at $25^{\circ} \mathrm{C}$ were shifted toward $4 \mathrm{C}$ and $8 \mathrm{C}$ respectively. This trend is shown in Fig. 3d. Moreover, an explicit maximum of improvement in C-rate capability was observed at all temperatures and the achievable improvements decreased again at very high C-rates. This indicates that the positive impact of anode structuring is visible at temperature and material specific discharge rates. At even higher C-rates, other limitations predominate and the associated homogenization of the charge carrier distribution in the electrolyte and in the electrode decreases.

It should be noted that the removal of a small fraction of the graphite coating (reduction of the ratio between anode and cathode capacity from 1.31 to 1.24 , see materials and methods section) results in a lower mass loading of the anode, which should generally lead to a slightly improved C-rate capability, even without the structures. Investigations to distinguish between the influence of mass loading reduction and the benefit of the structures by precise adjustment of the electrode parameters are currently underway and will be published shortly. However, previously published work on the electrochemical simulation of pore morphology modifications by laser structuring indicates that the 

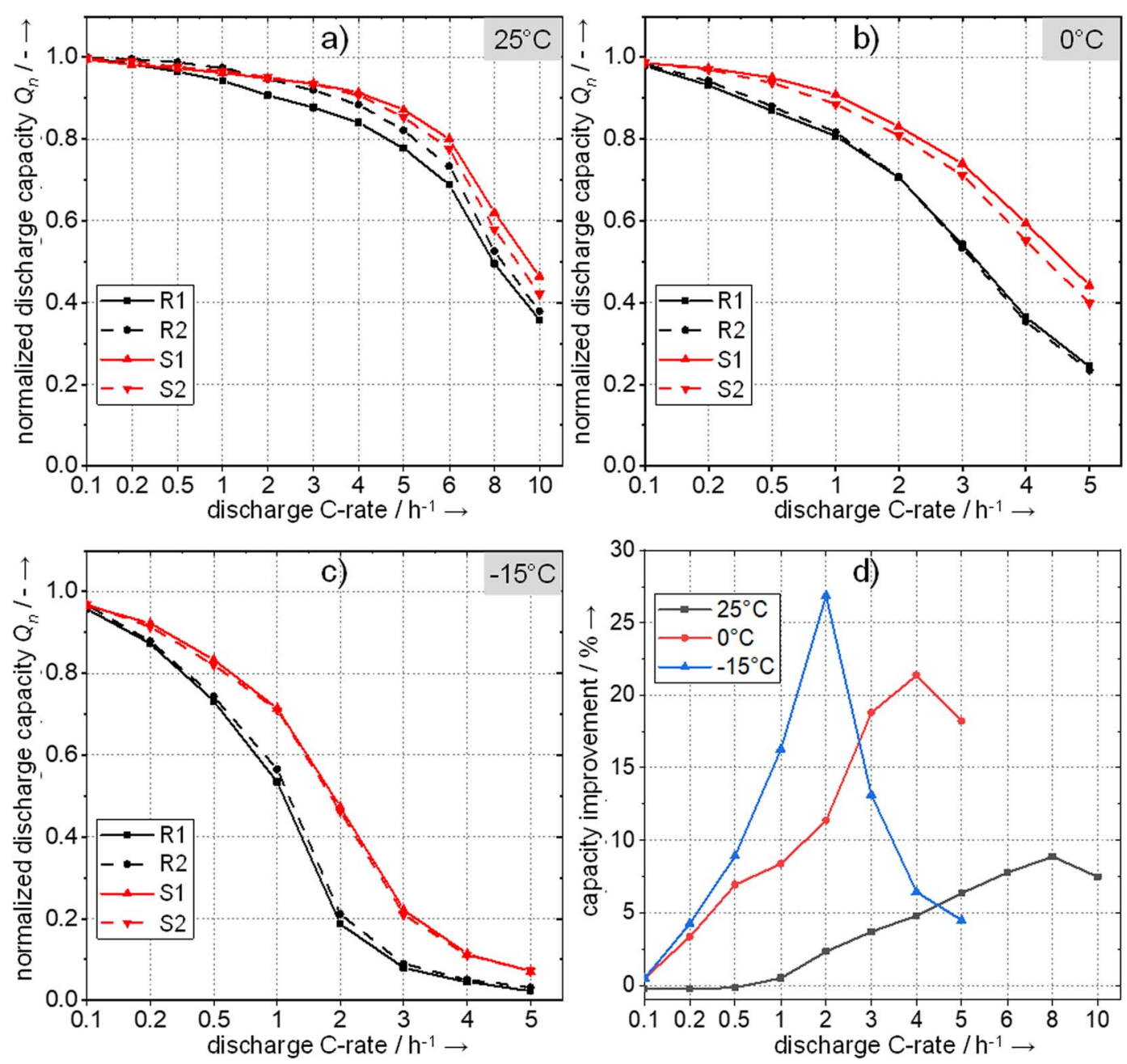

Figure 3. Normalized discharge capacities of laser-structured $(\mathrm{S} 1, \mathrm{~S} 2)$ and reference cells $(\mathrm{R} 1, \mathrm{R} 2)$ at different $\mathrm{C}$-rates for temperatures of a) $25^{\circ} \mathrm{C}$, b) $0^{\circ} \mathrm{C}$, and c) $-15^{\circ} \mathrm{C}$; in d), the mean improvements of the available capacity achieved by laser structuring are displayed.

electrode structure itself has a decisive influence on the cell performance. ${ }^{31}$ Also note, that anode overbalancing is typically used to prevent the occurrence of Li-plating. However, in the following section, we show that despite lower anode overbalancing, the structuring results in reduced Li-plating during fast charging. Laser structuring may therefore be a solution for eliminating the need for excessive overbalancing in future cell design.

\section{Reduction of Lithium-Plating}

As described in the introduction to this paper, there are several ways to electrochemically detect the occurrence of Li-plating in full cells. The measurement method described below to detect Li-plating was adapted from Uhlmann et al. ${ }^{7}$ and is illustrated in Fig. 4. The voltage relaxation of the full cell during a rest period after CCCV charging is considered. Depending on whether or not metallic lithium is plated at the anode during the charging process, there are clearly distinguishable relaxation voltage curves. ${ }^{41}$

If no Li-plating occurs, the voltage converges quasi-exponentially against a threshold value. This relaxation has its origin in the homogenization of the cell polarization in the electrodes and in the electrolyte. However, if Li-plating occurs during charging, these homogenization processes are superimposed by lithium re-intercalation in the relaxation phase (de-plating). The metallic lithium adhering to the anode surface decomposes and intercalates into the anode within a specific timespan that correlates with the amount of plated lithium. Since this process takes place at a different potential level, a characteristic tran- sient voltage plateau emerges, compare Fig. 4 . The voltage curves presented in Fig. 5 show the relaxation after previous charging (CCCV) at a temperature of $0^{\circ} \mathrm{C}$ for the two structured and the two conventional cells. These environmental conditions already pose a challenge for rapid charging, but at the same time are close to application in the field of electric mobility. At a temperature of $25^{\circ} \mathrm{C}$, either no Liplating could be provoked or detected during these tests (charging up to $2 \mathrm{C}$ ). Within preliminary tests, it could be shown that with a further increase of the charging current the upper cutoff voltage of $4.2 \mathrm{~V}$ was reached very quickly. Since the cells still had a very low SOC at that time, only a small amount of lithium had been transferred to the anode at all. However, since Li-plating occurs particularly at high SOCs (due to the approximation of the anode potential toward $0 \mathrm{~V}$ vs. lithium at high degrees of lithiation), no Li-plating could be detected. Therefore, the fast charge measurements at $25^{\circ} \mathrm{C}$ will not be discussed further.

Fig. 5a shows the voltage curve after a $0.1 \mathrm{C}$ charge, Fig. 5b after a $0.5 \mathrm{C}$ charge, Fig. $5 \mathrm{c}$ after a $1 \mathrm{C}$ charge, and Fig. $5 \mathrm{~d}$ after a $2 \mathrm{C}$ charge. For the two slower charging processes, the termination criterion of the $\mathrm{CV}$ phase was when the charge current fell below $0.05 \mathrm{C}$, while for the two faster charging processes, the termination criterion of the $\mathrm{CV}$ phase was set to $0.2 \mathrm{C}$. As the re-intercalation of lithium also occurs during the $\mathrm{CV}$ phase prior to the rest period, the latter termination criterion was chosen so that all $\mathrm{CV}$ phases lasted for a similar amount of time. Thus, even while fast charging, a significant re-intercalation of lithium during the $\mathrm{CV}$ phase could be avoided, which ensures the comparability of the results. After a $0.1 \mathrm{C}$ charge (Fig. 5a), both the structured and the 


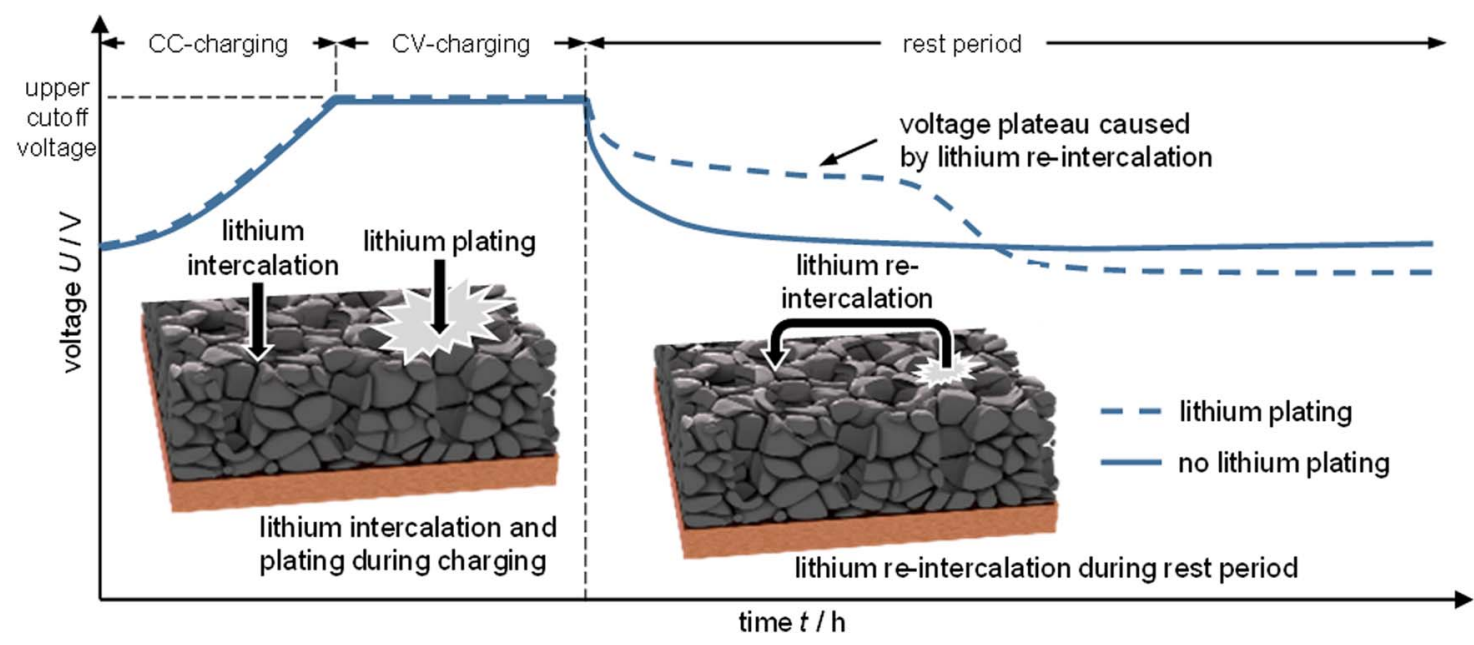

Figure 4. Schematic illustration of the Li-plating process with the corresponding voltage profile; in the rest period subsequent to charging, a voltage plateau is visible if Li-plating occurred during the previous charging process; this plateau forms due to the re-intercalation of the plated lithium into graphite, which takes place on a different potential level.
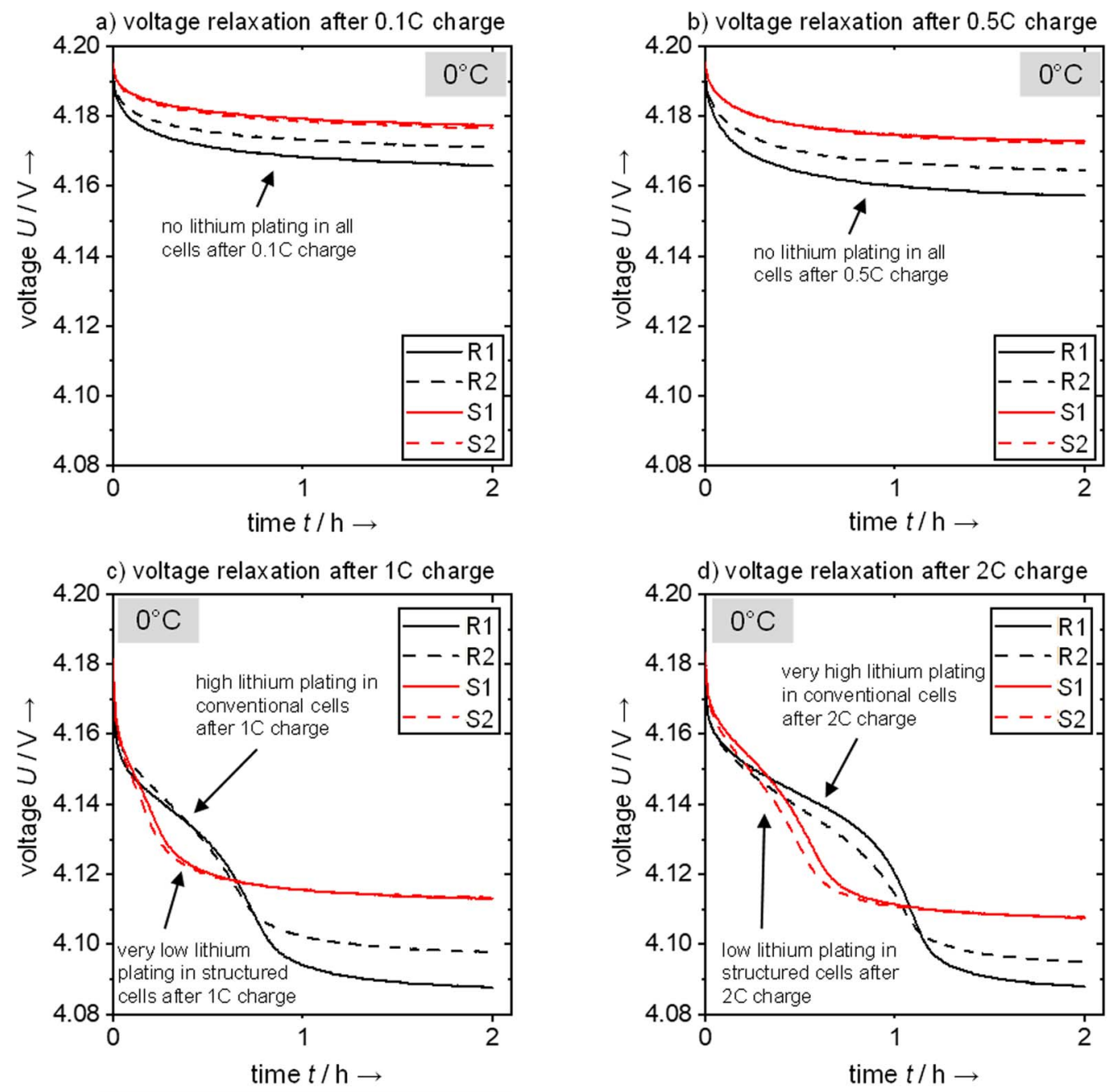

Figure 5. Voltage relaxation of conventional and laser-structured cells after $\mathrm{CCCV}$ charging at $0^{\circ} \mathrm{C}$; in the $\mathrm{CC}$ phase different currents were applied: a) $0.1 \mathrm{C}$ current in $\mathrm{CC}$ phase, $0.05 \mathrm{C}$ cutoff current in $\mathrm{CV}$ phase; b) $0.5 \mathrm{C}$ current in $\mathrm{CC}$ phase, $0.05 \mathrm{C}$ cutoff current in $\mathrm{CV}$ phase; $\mathrm{c}) 1 \mathrm{C}$ current in $\mathrm{CC}$ phase, $0.2 \mathrm{C}$ cutoff current in $\mathrm{CV}$ phase; d) $2 \mathrm{C}$ current in $\mathrm{CC}$ phase, $0.2 \mathrm{C}$ cutoff current in $\mathrm{CV}$ phase; the on-set of Li-plating was observed at significantly higher charging C-rates for laser-structured cells than for conventional cells taken from the voltage plateau caused by lithium re-intercalation; at very high charging C-rates, Li-plating is strongly reduced; voltage relaxation is generally lower for laser-structured cells, indicating a better fast charging capability. 
unstructured cells showed a voltage curve indicating that no Li-plating occurred during charging. However, a small difference of the final voltage after relaxation could be measured. While the OCV of the structured cells relaxed toward a voltage of approx. $4.18 \mathrm{~V}$, this value was $4.17 \mathrm{~V}$ for the unstructured cells. This indicates that already at low charge currents of only $0.1 \mathrm{C}$ a stronger polarization occurred in the conventional cells and that this polarization could be reduced by laser structuring. The course of the voltage during relaxation after a charge with a current of $0.5 \mathrm{C}$ (Fig. $5 \mathrm{~b}$ ) was very similar. No indications of Li-plating were observed. For charging with a current of $1 \mathrm{C}$ (Fig. 5c), significant differences in the voltage curves were visible. While the cells with laser-structured anodes maintained a quasi-exponential voltage relaxation, the conventional cells showed a distinct voltage plateau. This plateau lasted for about 30 minutes before the voltage relaxed against a final OCV in the range between $4.08 \mathrm{~V}$ and $4.10 \mathrm{~V}$ indicating the occurrence of Li-plating during charging. Furthermore, the duration of the persistence of the plateau gives an indication about the severity of Li-plating. The longer the period of re-intercalation, the more lithium was metallically deposited during the charging process. A charging current of $1 \mathrm{C}$ at $0^{\circ} \mathrm{C}$ which already led to strong Li-plating for the conventional cells was still uncritical for laser-structured cells. This demonstrates the high potential of laser structuring, as safety risks and ageing originating from Li-plating are reduced, which suggests that increased charging currents may be used in fast-charging applications. Li-plating was observed for both cell types at a charging current of $2 \mathrm{C}$ (Fig. 5d), whereby the amount of deposited lithium varied significantly. The re-intercalation plateau was present for more than one hour for the conventional cells, whereas it was considerably shortened (approx. 30 minutes) for the structured cells.

The effects described above become even more pronounced when the time derivative of the voltage curve is depicted. The corresponding differential voltage curves are shown in Fig. 6 . The end of the voltage plateau, which is expressed as a change in the slope of the voltage curve (cp. Fig 5), then appears as a local minimum and thus allows quantification of the completion of the lithium re-intercalation. In accordance to the slopes in Fig. 5a and Fig. 5b no pronounced minima are visible after charging with $0.1 \mathrm{C}$ and $0.5 \mathrm{C}$. On the contrary, Fig. $6 \mathrm{c}$ clearly shows that a small amount of metallic lithium was plated, leading to a local minimum in the case of the structured cells after a $1 \mathrm{C}$ charge. However, the degree of the Li-plating of the unstructured cells is distinctly higher. Similar characteristics can be observed after a $2 \mathrm{C}$ charge.

At a temperature of $-15^{\circ} \mathrm{C}$, all charge and mass transport processes are significantly slower. Preliminary tests showed that charging with
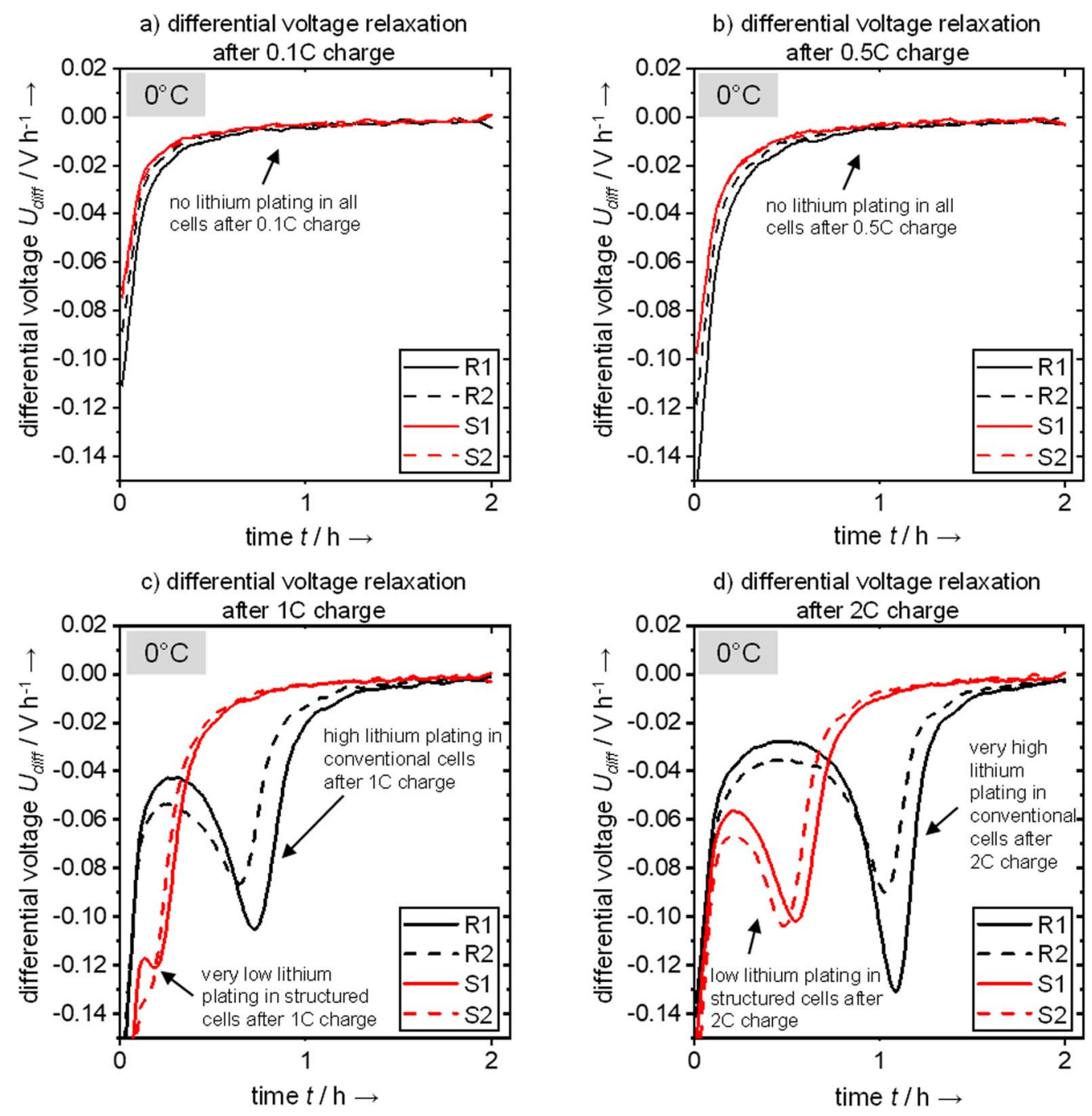

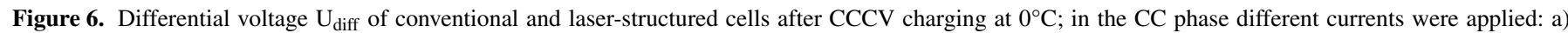

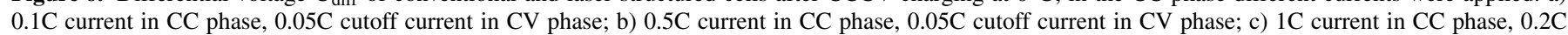

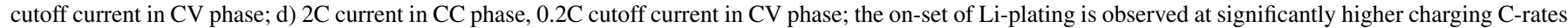

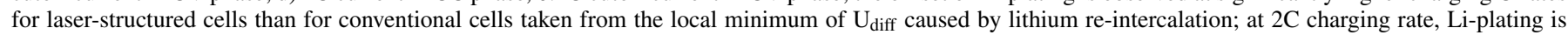
strongly reduced expressed by the shorter re-intercalation time. 
a) voltage relaxation after $0.1 \mathrm{C}$ charge

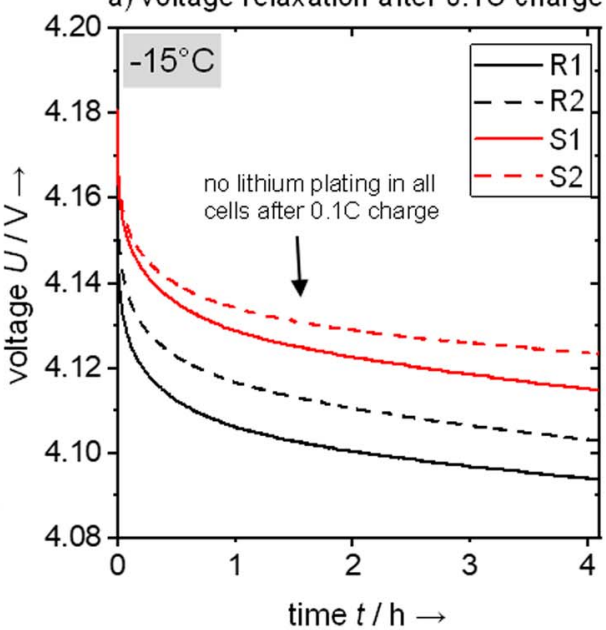

c) differential voltage relaxation after $0.1 \mathrm{C}$ charge

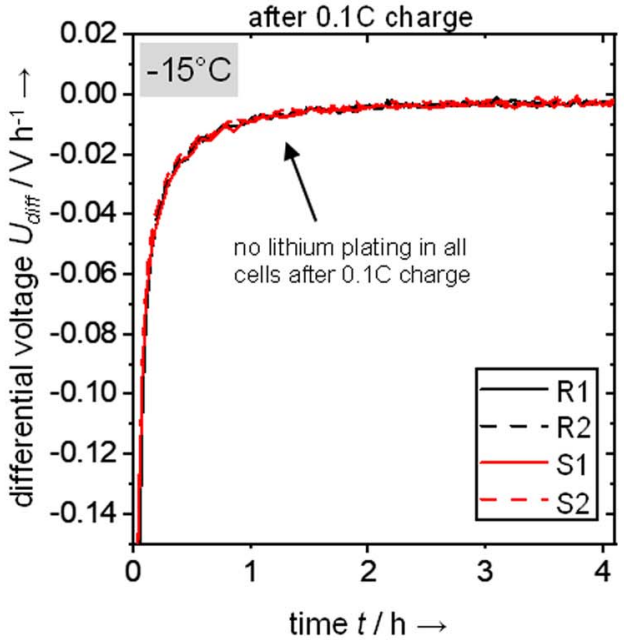

b) voltage relaxation after $0.5 \mathrm{C}$ charge

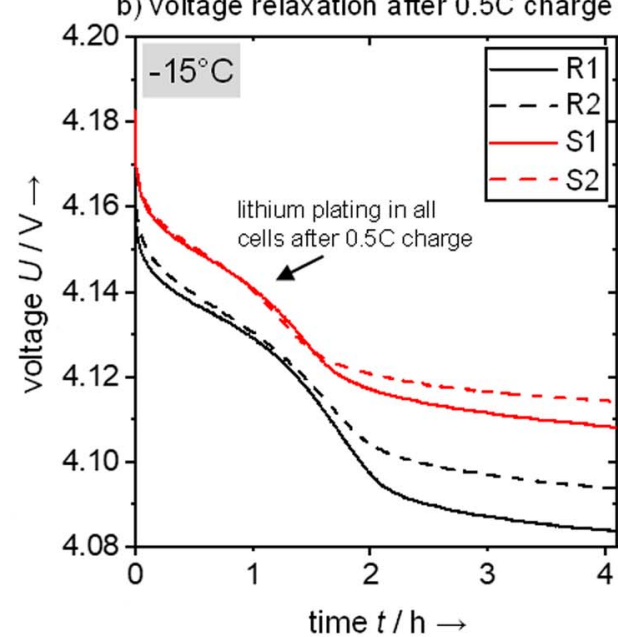

d) differential voltage relaxation after $0.5 \mathrm{C}$ charge

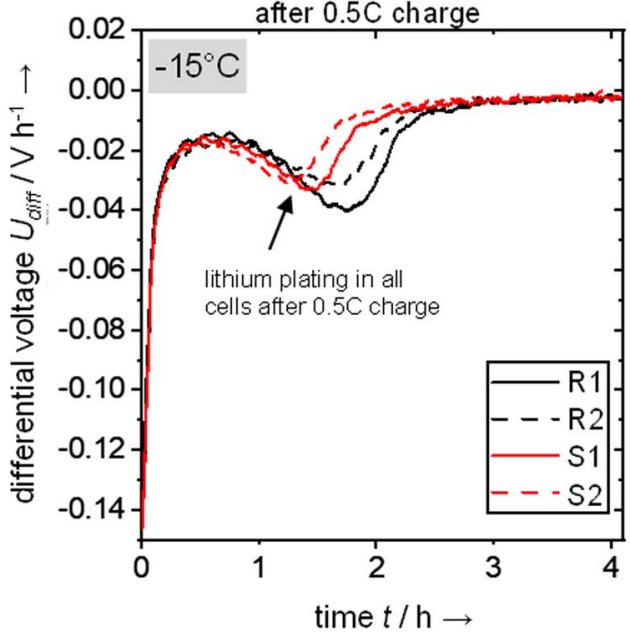

Figure 7. Voltage relaxation $(a, b)$ and corresponding differential voltage relaxation $(c, d)$ of conventional and laser-structured cells after charging with different currents at $-15^{\circ} \mathrm{C}$; the beneficial effects of laser structuring seen at $0^{\circ} \mathrm{C}$ are far less pronounced at $-15^{\circ} \mathrm{C}$ indicating that other shares of the cell resistance become dominant.

$1 \mathrm{C}$ and $2 \mathrm{C}$ lead to a fast increase in cell voltage and to a premature reach of the upper cutoff voltage. Thereby, no SOC higher than $50 \%$ could be reached in the $\mathrm{CC}$ phase. In this SOC range, no evidence of Li-plating was detectable. The authors attribute this to the low SOC of the cells at which Li-plating is unlikely to occur. Therefore, only the relaxation processes after $0.1 \mathrm{C}$ and $0.5 \mathrm{C}$ charging are described below. The results are presented together with the time derivative of the voltage curves in Fig. 7. It becomes evident that at a charging current of $0.1 \mathrm{C}$, Li-plating did not occur in either the conventional cells or the cells with structured anodes. This conclusion can be drawn from the voltage relaxation (Fig. 7a) as well as the time derivative (Fig. 7c), where no local minimum is apparent. When charged with $0.5 \mathrm{C}$, both cell types showed indications of Li-plating, expressed by the distinctive voltage plateaus (Fig. 7b) and the respective local minima in the differential voltage curves (Fig. 7d). Again, the trend toward reduced Li-plating of the structured cells can be observed, but less pronounced than at an ambient temperature of $0^{\circ} \mathrm{C}$. Apparently, the reduction of the internal resistance by structuring is not as effective at $-15^{\circ} \mathrm{C}$. This may indicate that other cell internal processes, e.g. lithium diffusion within the graphite particles or at the phase boundaries between the electrolyte and the active materials, have a limiting effect. Thus, the ion transport in the electrolyte within the tortuous electrode structure no longer appears to be the limiting process. It should be noted that the re-intercalation process generally takes much longer at $-15^{\circ} \mathrm{C}$.
After charging with $0.5 \mathrm{C}$ the re-intercalation takes approx. 1.5 hours for the structured cells and approx. 2 hours for the conventional cells. More detailed measurements with a higher resolution in the examined charging rates are required to determine the $\mathrm{C}$-rate at which Li-plating first occurs at $-15^{\circ} \mathrm{C}$ for both cell types.

\section{Improvement of Fast Charging}

As described in the previous sections, laser structuring reduces the mean tortuosity of the anode, resulting in lower overpotentials and lithium concentration gradients during charging and discharging. The lower overpotentials imply that the upper cutoff voltage during CC charging is reached at a higher SOC for cells with laser-structured anodes for a given charging current. As a result, the duration of the subsequent $\mathrm{CV}$ phase is reduced since a smaller amount of charge is necessary to reach an SOC of $100 \%$. The respective charging times in the CC and CV phase were measured for the four cells S1, S2, R1, and R2. The results are shown in Fig. 8 for an ambient temperature of $0^{\circ} \mathrm{C}$

The laser structuring of the anodes and the associated change in the $\mathrm{CC} / \mathrm{CV}$ ratio led to a significantly reduced time to achieve an SOC of $100 \%$. While the conventional cells needed about 2.4 hours to be fully charged at a charge current of $0.5 \mathrm{C}$, the structured cells required only 2.0 hours (Fig. 8a). To further investigate this, the SOC at which the 
a)

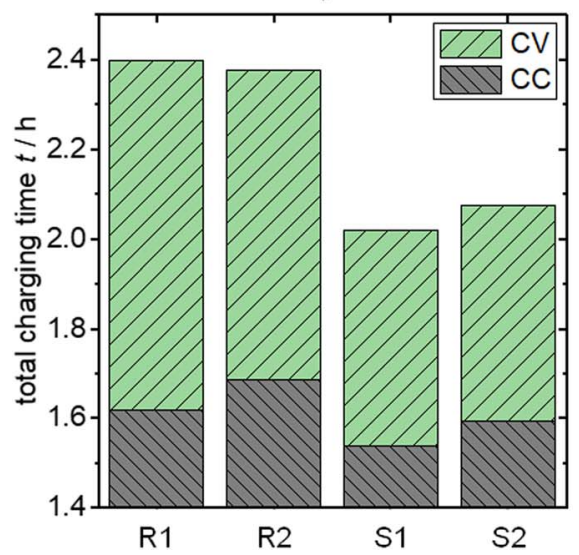

b)

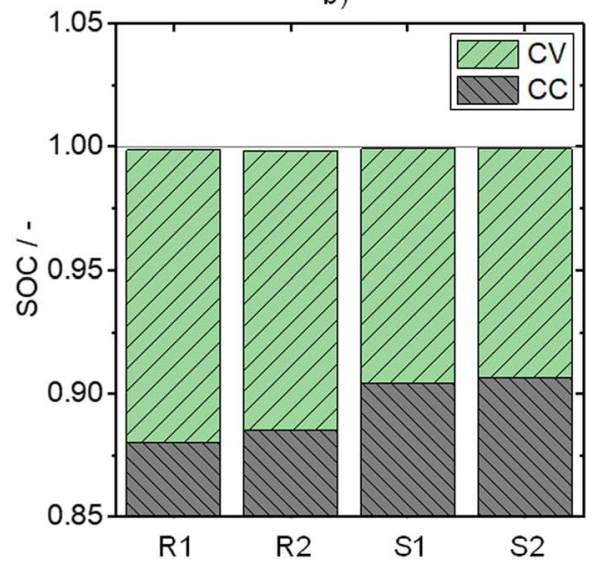

Figure 8. a) Charging times separated into the CC phase and the CV phase for laser-structured and conventional cells; b) achieved SOC separated into CC phase and $\mathrm{CV}$ phase. $\mathrm{CC}$ charging was $0.5 \mathrm{C}$ at $0^{\circ} \mathrm{C}$. A reduction in charging time from approx. $2.4 \mathrm{~h}$ down to approx. $2.0 \mathrm{~h}$ was achieved, since higher SOCs were reached in the CC phase, reducing the remaining charging capacity for the CV phase significantly. An SOC of nearly $100 \%$ was achieved for all cells. No Li-plating occurred in the cells (cp. Fig. 5 and Fig. 6).

CV phase begins was examined (Fig. 8b). The results show that the CV phase does not start before an SOC of approx. $90 \%$ compared to approx. $88 \%$ for the conventional cells. Since the charge current drops rapidly at the beginning of the $\mathrm{CV}$ phase, substantially more time is required to reach the final SOC of $100 \%$. This comparison proves that the laser structuring of anodes can have a significant positive influence on the charging time of lithium-ion cells, even in operating conditions that do not cause Li-plating.

\section{Conclusions and Future Work}

In this publication, the influence of laser structuring of the graphite anodes on the operating characteristics of LIBs was assessed. By using electrochemical impedance spectroscopy it was shown that the cell impedance and specifically the charge transfer resistance was significantly reduced by laser structuring. This was attributed to a reduced mean tortuosity that facilitated lithium transport as well as an increased mean porosity which provided a higher surface area for charge transfer. The laser structuring had a positive effect on both the discharge and charge process of the cell. For discharging, it was demonstrated that the amount of capacity and therefore energy provided was distinctly increased. This effect was particularly pronounced at low temperatures. The maximum improvements in deployable capacity were observed at varying discharge $\mathrm{C}$-rates depending on the ambient temperature. At this point we would like to point out once again that some of these improvements were due to the slight reduction in the active material loading of the anode due to laser structuring. However, previously published work in the field of electrochemical simulation suggests that a directional porosity intentionally created by laser structuring has further positive impact. ${ }^{31,33}$ In addition, the rapid charging behavior of the two cell types was investigated. A special focus was placed on the detection of Li-plating at different ambient temperatures and charging rates. Analyzing the OCV behavior after charging indicated that Li-plating could be avoided or strongly reduced by laser structuring. With a view to an automotive application, this may provide the possibility to carry out charging processes of the vehicle faster at low temperatures without the risk of provoking Li-plating. Furthermore, reduced charging times were measured, even under charging conditions uncritical with regard to Li-plating. The increased fast charging capability of the cells through the modification of the electrode design offers considerable potential for automotive applications. Particularly considering the trend toward higher energy densities of the electrodes, e.g. through higher densification or higher active material layer thicknesses, laser structuring can be an important approach for maintaining electrodes with high current capability. In future work, the authors will focus on the quantitative and locally resolved measure- ment of Li-plating in LIBs with laser-structured anodes. This includes both measurements with reference electrodes for monitoring the individual electrode potentials and post-mortem investigations. Furthermore, lifetime tests will be performed describing the effects of reduced Li-plating on the cyclic ageing of the cells. Ultimately, the scaling of the laser structuring process toward economic structuring speeds is required.

\section{Acknowledgments}

This work was financially supported by the German Federal Ministry of Education and Research (BMBF) under grant number 03CP0081 (ExZellTUM II) as well as the German Federal Ministry of Economic Affairs and Energy (BMWi) under grant number 03ET6103F (SurfaLIB). The authors gratefully acknowledge the support. The authors also thank Gamry Instruments for the loan of the potentiostat. There are no conflicts to declare.

\section{ORCID}

Jan Bernd Habedank (D) https://orcid.org/0000-0003-2057-7037

\section{References}

1. K. G. Gallagher, S. E. Trask, C. Bauer, T. Woehrle, S. F. Lux, M. Tschech, P. Lamp, B. J. Polzin, S. Ha, B. Long, Q. Wu, W. Lu, D. W. Dees, and A. N. Jansen, J. Electrochem. Soc., 163, A138 (2015).

2. Q. Liu, C. Du, B. Shen, P. Zuo, X. Cheng, Y. Ma, G. Yin, and Y. Gao, RSC Adv., 6, 88683 (2016)

3. F. Jiang and P. Peng, Scientific Reports, 6, 32639 (2016).

4. X.-G. Yang, Y. Leng, G. Zhang, S. Ge, and C.-Y. Wang, Journal of Power Sources, 360, 28 (2017).

5. M. Broussely, P. Biensan, F. Bonhomme, P. Blanchard, S. Herreyre, K. Nechev, and R. J. Staniewicz, Journal of Power Sources, 146, 90 (2005).

6. V. Zinth, C. von Lüders, M. Hofmann, J. Hattendorff, I. Buchberger, S. Erhard, J. Rebelo-Kornmeier, A. Jossen, and R. Gilles, Journal of Power Sources, 271, 152 (2014).

7. C. Uhlmann, J. Illig, M. Ender, R. Schuster, and E. Ivers-Tiffée, Journal of Power Sources, 279, 428 (2015).

8. M. C. Smart, B. V. Ratnakumar, L. Whitcanack, K. Chin, M. Rodriguez, and S. Surampudi, IEEE Aerosp. Electron. Syst. Mag., 17, 16 (2002).

9. M. C. Smart and B. V. Ratnakumar, J. Electrochem. Soc., 158, A379 (2011)

10. M. Petzl and M. A. Danzer, Journal of Power Sources, 254, 80 (2014).

11. S. Schindler, M. Bauer, M. Petzl, and M. A. Danzer, Journal of Power Sources, 304 170 (2016).

12. J. Landesfeind, J. Hattendorff, A. Ehrl, W. A. Wall, and H. A. Gasteiger, J. Electrochem. Soc., 163, A1373 (2016)

13. V. Zinth, C. von Lüders, J. Wilhelm, S. V. Erhard, M. Hofmann, S. Seidlmayer, J. Rebelo-Kornmeier, W. Gan, A. Jossen, and R. Gilles, Journal of Power Sources, 361, 54 (2017). 
14. A. Nyman, T. G. Zavalis, R. Elger, M. Behm, and G. Lindbergh, J. Electrochem. Soc., 157, A1236 (2010)

15. A. D. Jara, A. Betemariam, G. Woldetinsae, and J. Y. Kim, International Journal of Mining Science and Technology, 29, 671 (2019).

16. T. Günther, N. Billot, J. Schuster, J. Schnell, F. B. Spingler, and H. A. Gasteiger, $A M R$, 1140, 304 (2016).

17. M. Ebner, D.-W. Chung, R. E. García, and V. Wood, Adv. Energy Mater., 4, 1301278 (2014).

18. D. D. Macdonald, Electrochimica Acta, 51, 1376 (2006).

19. F. J. Günter, J. B. Habedank, D. Schreiner, T. Neuwirth, R. Gilles, and G. Reinhart, J. Electrochem. Soc., 165, A3249 (2018).

20. T. Momma, M. Matsunaga, D. Mukoyama, and T. Osaka, Journal of Power Sources, 216, 304 (2012).

21. S. S. Zhang, K. Xu, and T. R. Jow, Electrochimica Acta, 49, 1057 (2004).

22. M. Itagaki, K. Honda, Y. Hoshi, and I. Shitanda, Journal of Electroanalytical Chemistry, 737, 78 (2015).

23. D. Andre, M. Meiler, K. Steiner, C. Wimmer, T. Soczka-Guth, and D. U. Sauer, Journal of Power Sources, 196, 5334 (2011).

24. S. S. Zhang, K. Xu, and T. R. Jow, Electrochemistry Communications, 4, 928 (2002).

25. M. Itagaki, N. Kobari, S. Yotsuda, K. Watanabe, S. Kinoshita, and M. Ue, Journal of Power Sources, 135, 255 (2004).

26. C. H. Chen, J. Liu, and K. Amine, Journal of Power Sources, 96, 321 (2001).

27. P. L. Moss, G. Au, E. J. Plichta, and J. P. Zheng, Journal of Power Sources, 155, A986 (2008)
28. G. Ning, B. Haran, and B. N. Popov, Journal of Power Sources, 117, 160 (2003).

29. J. B. Habedank, J. Endres, P. Schmitz, M. F. Zaeh, and H. P. Huber, Journal of Laser Applications, 30, 32205 (2018).

30. J. B. Habedank, L. Kraft, A. Rheinfeld, C. Krezdorn, A. Jossen, and M. F. Zaeh, J. Electrochem. Soc., 165, A1563 (2018)

31. L. Kraft, J. B. Habedank, A. Frank, A. Rheinfeld, and A. Jossen, J. Electrochem. Soc., 167, $13506(2020)$

32. R. Morasch, B. Suthar, J. B. Habedank, J. Landesfeind, M. F. Zaeh, and H. A. Gasteiger, ModVal (2018).

33. V. P. Nemani, S. J. Harris, and K. C. Smith, J. Electrochem. Soc., 162, A1415 (2015).

34. C. L. Cobb and M. Blanco, Journal of Power Sources, 249, 357 (2014).

35. C.-J. Bae, C. K. Erdonmez, J. W. Halloran, and Y.-M. Chiang, Advanced Materials, 25, 1254 (2013)

36. M. S. Saleh, J. Li, J. Park, and R. Panat, Additive Manufacturing, 23, 70 (2018).

37. D. L. Wood, J. Li, and C. Daniel, Journal of Power Sources, 275, 234 (2015).

38. W. Pfleging, Nanophotonics, 7, 13 (2018).

39. J. B. Habedank, F. J. Günter, N. Billot, R. Gilles, T. Neuwirth, G. Reinhart, and M. F. Zaeh, Int J Adv Manuf Technol, 102, 2769 (2019).

40. J. Song and M. Z. Bazant, J. Electrochem. Soc., 160, A15 (2013).

41. C. von Lüders, V. Zinth, S. V. Erhard, P. J. Osswald, M. Hofmann, R. Gilles, and A. Jossen, Journal of Power Sources, 342, 17 (2017). 